ఠ

\title{
Newly emergent acquired EGFR exon 18 G724S mutation after resistance of a T790M specific EGFR inhibitor osimertinib in non-small-cell lung
}

\section{cancer: a case report}

This article was published in the following Dove Medical Press journal:

OncoTargets and Therapy

\section{Yan Zhang' \\ Bixiu $\mathrm{He}^{2}$ \\ Dongbo Zhou ${ }^{2}$ \\ Min $\mathrm{Li}^{\prime}$ \\ Chengping $\mathrm{Hu}^{\prime}$}

'Department of Respiratory Medicine, Xiangya Hospital (Key Cite of National Clinical Research Center for Respiratory Disease), Central South University, Changsha, Hunan, P.R. China; ${ }^{2}$ Department of Gerontology, Xiangya Hospital, Central South University, Changsha, Hunan, P.R. China
Correspondence: Min Li; Chengping Hu Department of Respiratory Medicine, Xiangya Hospital (Key Cite of National Clinical Research Center for Respiratory Disease), Central South University, 87 Xiangya Road, Changsha, Hunan 4I0008, P.R. China

Tel +86 I 3787 I0 3054;

+86 I3508488068

Email limin2050@csu.edu.cn; huchengp28@csu.edu.cn
Background: T790M mutation is well known as the most common mechanism for resistance to the first- and second-generation tyrosine kinase inhibitors (TKIs) for EGFR mutation in nonsmall-cell lung cancer. Several third-generation EGFR TKIs, such as osimertinib, have been explored and approved for conquering this resistance; however, acquired resistance to osimertinib is evident and the resistance mechanisms remain complex and incompletely explored.

Case presentation: A non-smoking 58-year-old female patient was initially diagnosed with lung adenocarcinoma harboring EGFR exon 19 deletion and clinically responded to initial gefitinib treatment. The patient progressed on gefitinib after $>1$ year and a T790M mutation was detected in tissue biopsy by next-generation sequencing (NGS). Osimertinib treatment was administrated for several months and an acquired rare EGFR G724S mutation was detected via NGS blood sample after osimertinib resistance.

Conclusion: The specific mechanisms of acquiring drug resistance for EGFR-TKIs have not been fully explored. EGFR G724S mutation might be associated with osimertinib resistance but more studies about the mechanism should be explored.

Keywords: NSCLC, EGFR mutation, tyrosine kinase inhibitor, next-generation sequencing

\section{Background}

EGFR gene mutations in lung adenocarcinoma are closely related to the clinical efficacy of EGFR tyrosine kinase inhibitors (TKIs). Commonly used EGFR-TKIs include gefitinib, erlotinib (and icotinib) as the first-generation EGFR-TKIs, and afatinib (and dacomitinib) as the second generation, and osimertinib as the third generation. Furthermore, many clinical trials have demonstrated that EGFR-TKIs significantly increased clinical benefits compared with the standard chemotherapies in non-smallcell lung cancer (NSCLC) patients. ${ }^{1,2}$ However, most NSCLC patients eventually developed resistance to these first-generation TKIs within 1 year. The EGFR exon 20 T790M mutation has been well known as the major resistant mutation for the first- and second-generation TKIs. ${ }^{3}$ Approximately $50 \%$ of the patients with TKI resistance were detected of harboring the EGFR T790M mutation. ${ }^{4}$ Several third-generation EGFRmutant selective TKIs, such as osimertinib (AZD9291), olmutinib (HM61713), and rociletinib, are being developed for EGFR T790M mutation in NSCLC. Osimertinib targets both sensitive EGFR mutation and resistant T790M, and a better benefit of progression-free survival (PFS) was observed in osimertinib (mPFS 18.9 months) 
when compared to a standard first-generation EGFR-TKI (gefitinib or erlotinib, 10.2 months). ${ }^{5}$ Even so, most patients who were given the third-generation EGFR-TKIs would eventually develop resistance after several months. Acquired resistant C797S mutation, also located in EGFR exon 20, has been reported as one of the most important resistance mechanisms of osimertinib, ${ }^{6,7}$ and C797S mutation was also reported as acquired resistance to another T790M-specific third-generation EGFR-TKI (HM61713) in NSCLC. ${ }^{8}$ Other mechanisms of resistance to osimertinib are reported, such as MET and HER2 amplification and small-cell lung cancer transformation. ${ }^{5,9}$ EGFR L718Q has also been found in T790M-positive patients after osimertinib resistance. ${ }^{10}$ Here, we report an extremely rare and complicated acquired mutation of EGFR exon 18 G724S after osimertinib resistance.

\section{Case presentation}

A non-smoking 58-year-old female was diagnosed with lung adenocarcinoma (pT2N0M0, according to seventh TNM classification) after right lower lobe lobectomy. A SurPlex ${ }^{\mathrm{TM}}$ liquid chip test (SurPlex ${ }^{\mathrm{TM}}$-xTAG, Surexam, P.R. China) was performed on the resected tumor tissue, which showed an activated mutation of EGFR exon 19 deletion (19 Del, p.E746_S752>V), no KRAS, BRAF, PIK3CA mutation. The patient was administered with gefitinib at a dose of $250 \mathrm{mg} /$ day for 1 year, during which the patient was stable (according to the Response Evaluation Criteria in Solid Tumors). Gefitinib therapy was discontinued after appearance of liver metastasis in December 2013, and second-line chemotherapy (pemetrexed $850 \mathrm{mg}$, d1+ cisplatin $40 \mathrm{mg}$, d1-d3) and percutaneous microwave coagulation therapy of liver were administrated. However, the patient discontinued the chemotherapy after two cycles due to serious adverse effects of nausea and vomiting and continued with gefitinib treatment again. New liver metastases and a pulmonary mass were detected in March 2015. Wedge resection of left upper lobe was carried out by video-assisted thoracoscopic surgery and pathological diagnosis was adenocarcinoma (pT2NxM1, IV stage). Next-generation sequencing (NGS, Langqing ${ }^{\mathrm{TM}}$, Burning Rock Dx, P.R. China) of the tumor biopsy presented EGFR 19 Del and T790M mutation, MAP2K1 and TP53 mutation, no ALK and ROS1 mutation. The patient was enrolled in the Phase II clinical trial of osimertinib (40 mg/day) instead of gefitinib therapy. The patient progressed with brain metastasis in June 2015 and withdrew from the clinical trial and changed dose of osimertinib from $40 \mathrm{mg} /$ day to standard $80 \mathrm{mg} /$ day, complementary with stereotactic brain irradiation. The patient developed multiple metastases after several months and the peripheral blood NGS test (Langqing ${ }^{\mathrm{TM}}$ ) showed rare EGFR G724S on 2 June 2016 (in addition to EGFR 19 Del and T790M). Then, the therapy combined osimertinib $80 \mathrm{mg}$ /day and gefitinib $250 \mathrm{mg} /$ day. Moreover, the patient's family purchased pembrolizumab and cabozantinib (XL184) from outside China, which also failed to slow down the progress of the disease. Two additional peripheral blood NGS tests revealed MET amplification in August and September 2016. However, the disease worsened quickly and the patient died of respiratory failure on 25 September 2016. All the processes of diagnosis and treatment are shown below (Figure 1 and Table 1).

\section{Discussion}

T790M mutation is well known as the most common resistant mutation for the first- and second-generation TKIs for EGFR mutation. ${ }^{11}$ Osimertinib as a selective third-generation TKI has been explored and approved for treating EGFR T790M in NSCLC patients. A better clinical response was also observed in osimertinib group compared to gefitinib and/or erlotinib group in untreated EGFR-mutant advanced NSCLC. ${ }^{5}$ However, similar to patients treated with first- or secondgeneration EGFR TKIs, resistance eventually occurred in patients treated with osimertinib after no $>10$ months. ${ }^{12}$ Several mechanisms of resistance including EGFR-dependent and EGFR-independent were reported. EGFR exon 20 C797S was reported to be a major resistance mechanism to osimertinib as an EGFR-dependent mechanism. ${ }^{8,13,14}$ EGFR C797S codon, located in the kinase-binding pocket, results in loss of binding of osimertinib to EGFR. Similarly, C797S has also been detected in EGFR T790M patients with rociletinib, olmutinib, and nazartinib treatment. ${ }^{8,15,16}$ However, there are still numerous patients who have acquired resistance to these third-generation TKIs without acquiring C797S mutation. ${ }^{13}$ More recently, a novel EGFR C797G mutation has been reported after osimertinib resistance. ${ }^{17}$ Other rare EGFR mutations, including G796S/R, L792F/H, L798I, and L718Q, have also been reported to be possible resistance mutations to osimertinib. ${ }^{10,18-20}$ EGFR T790M loss was often seen early after osimertinib treatment and was accompanied by osimertinib resistance in a shorter time compared to those with maintained T790M. ${ }^{21}$ EGFR-independent mechanisms have been reported in tumor or plasma samples, including MET and HER-2 amplification, ${ }^{22}$ MAPK activation, ${ }^{23}$ mutations in $\mathrm{KRAS},{ }^{15} \mathrm{PI} 3 \mathrm{KCA},{ }^{16} \mathrm{BRAF},{ }^{24}$ and transformation to small-cell lung cancer. ${ }^{25}$

Herein, we report that EGFR exon 18 G724S may serve as an acquired potential resistance mutation in a 


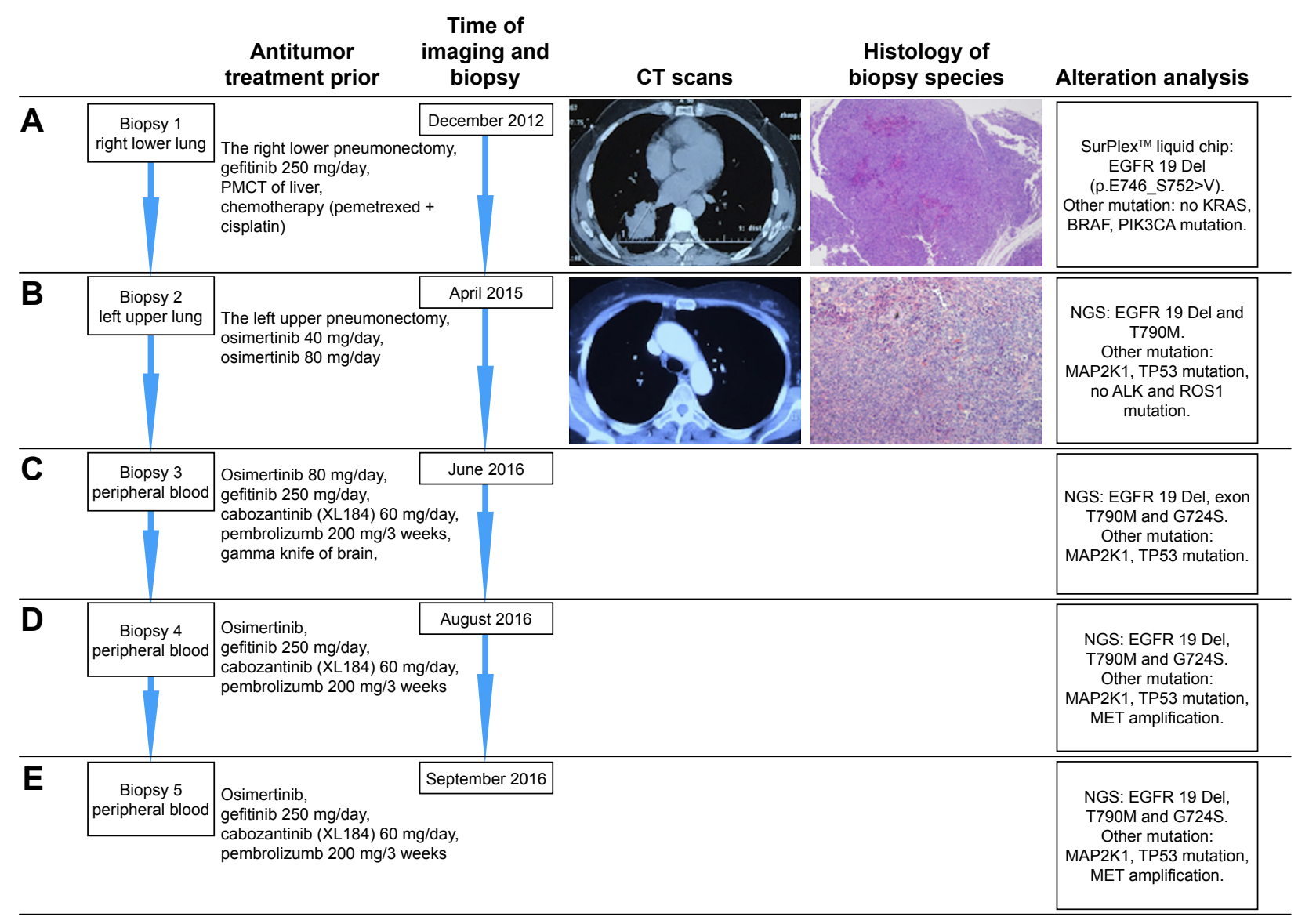

Figure I Patient's clinical course including treatment history and relevant imaging studies and tumor biopsy specimen studies.

Notes: (A) The patient was diagnosed with lung adenocarcinoma harboring EGFR 19 Del in December 2012 and was administrated with gefitinib treatment. (B) NGS of tumor biopsy in April 2015 showed EGFR T790M in addition to EGFR 19 Del and the patient was administrated with osimertinib. (C) NGS of blood sample in June 2016 showed an acquired G724S mutation, MAP2KI and TP53 mutation along with the EGFR 19 Del and T790M mutation. The patient was treated with osimertinib, gefitinib, cabozantinib, and pembrolizumab. (D and E) NGS of blood sample in August and September 2016 showed additional MET amplification.

Abbreviations: PMCT, percutaneous microwave coagulation therapy; NGS, next-generation sequencing.

lung adenocarcinoma post progression of osimertinib. In this case report, G724S mutation clearly emerged after osimertinib resistance, as the same genomic profiling assay was performed in the tumor tissues before osimertinib treatment and this mutation was not detected. G724S mutation was detected in two cases of NSCLC after osimertinib resistance. ${ }^{26}$ In another case report of lung adenocarcinoma, even though EGFR G724S was detected before osimertinib

Table I Gene mutations from tumor biopsy specimen or peripheral blood

\begin{tabular}{|c|c|c|c|c|c|c|c|c|}
\hline Gene & Exon & $\begin{array}{l}\text { Amino } \\
\text { acid }\end{array}$ & Nucleotide & $\begin{array}{l}\text { December } \\
2012 \text { (tumor } \\
\text { tissue: } \\
\text { SurPlex }{ }^{\mathrm{TM}} \\
\text { liquid chip test }\end{array}$ & $\begin{array}{l}\text { AF\%, April } \\
2015 \text { (left } \\
\text { lung mass: } \\
\text { NGS) }\end{array}$ & $\begin{array}{l}\text { AF\%, } \\
\text { June } 2016 \\
\text { (peripheral } \\
\text { blood: NGS) }\end{array}$ & $\begin{array}{l}\text { AF\%, } \\
\text { August } 2016 \\
\text { (peripheral } \\
\text { blood: NGS) }\end{array}$ & $\begin{array}{l}\text { AF\%, } \\
\text { September } \\
2016 \\
\text { (peripheral } \\
\text { blood: NGS) }\end{array}$ \\
\hline \multirow[t]{3}{*}{ EGFR } & 19 & & $\begin{array}{l}\text { 2237-2255del AATTAA } \\
\text { GAGAAGCAACATCinsT }\end{array}$ & $\begin{array}{l}\text { Exon } 19 \text { del } \\
(\text { p.E746-S752>V) }\end{array}$ & 15.2 & 5.33 & 7.97 & 15.6 \\
\hline & 20 & T790M & $2369 C>T$ & & 11.5 & 1.34 & 5.37 & 8.42 \\
\hline & 18 & G724S & $2170 G>A$ & & & 1.56 & 0.89 & 0.97 \\
\hline $\begin{array}{l}\text { MAP2KI } \\
(\text { MEKI) }\end{array}$ & 2 & D67E & $201 C>A$ & & 16.1 & 2.88 & 11.9 & 21.8 \\
\hline TP53 & & & c.764-766del & & 13.4 & 20.42 & 10.6 & 3.33 \\
\hline MET & & & & & & & $C N=2.46$ & $C N=3.01$ \\
\hline
\end{tabular}

Abbreviations: AF, allelic frequency; NGS, next-generation sequencing. 
Table 2 General clinical characteristics of patients harboring the EGFR G724S mutation after TKIs treatment

\begin{tabular}{|c|c|c|c|c|c|c|c|}
\hline Case & Sex/age & $\begin{array}{l}\text { Smoking } \\
\text { status }\end{array}$ & Stage & $\begin{array}{l}\text { Firstly detected } \\
\text { EGFR mutation/TKIs }\end{array}$ & $\begin{array}{l}\text { Secondly detected } \\
\text { EGFR mutation/ } \\
\text { TKIs }\end{array}$ & $\begin{array}{l}\text { Thirdly detected } \\
\text { EGFR mutation }\end{array}$ & G724S (MAF) \\
\hline Our case & $F / 58$ & Never & $\mathrm{II} \rightarrow \mathrm{IV}$ & Exon $19 \mathrm{Del} /$ gefitinib & T790M/osimertinib & G724S & I.56/0.89/0.97 \\
\hline Oztan ${ }^{26}$ & $\mathrm{~F} / 47$ & - & IV & $\begin{array}{l}\text { Exon } 19 \text { Del/erlotinib } \\
\rightarrow \text { afatinib }\end{array}$ & T790M/osimertinib & G724S & $5 \%$ \\
\hline Oztan ${ }^{26}$ & $M / 74$ & - & IV & Exon 19 Del/erlotinib & _losimertinib & G724S & $0.7 \%$ \\
\hline Peled $^{27}$ & $\mathrm{~F} / 49$ & Never & IIIA & Exon $19 \mathrm{Del} /$ gefitinib & T790M/G724S & - & $2.9 \%$ \\
\hline $\mathrm{Li}^{28}$ & - & - & - & $\begin{array}{l}\text { Exon } 19 \text { Del/gefitinib or } \\
\text { erlotinib }\end{array}$ & T790M/G724S & - & $10.1 \%$ \\
\hline $\mathrm{Li}^{28}$ & - & - & - & $\begin{array}{l}\text { Exon Del/gefitinib or } \\
\text { erlotinib }\end{array}$ & - & G724S & $1.4 \%$ \\
\hline $\mathrm{Li}^{28}$ & - & - & - & $\begin{array}{l}\text { Exon } 19 \text { Del/gefitinib or } \\
\text { erlotinib }\end{array}$ & - & G724S & $80.5 \%$ \\
\hline $\mathrm{Li}^{28}$ & - & - & - & $\begin{array}{l}\text { Exon } 19 \text { Del/gefitinib or } \\
\text { erlotinib }\end{array}$ & - & G724S & $37.9 \%$ \\
\hline $\mathrm{Li}^{28}$ & - & - & - & $\begin{array}{l}\text { Exon } 19 \text { Del/gefitinib or } \\
\text { erlotinib }\end{array}$ & - & G724S & $59.9 \%$ \\
\hline Fassunke $^{29}$ & $F / 59$ & - & IIIA & _/erlotinib & T790M/osimertinib & G724S & $6.3 \%$ \\
\hline Fassunke $^{29}$ & $\mathrm{~F} / 47$ & _- & IV & _lerlotinib & T790M/EGF8I6 & G724S & $71.1 \%$ \\
\hline Fassunke $^{29}$ & $\mathrm{~F} / 68$ & - & IV & _lgefitinib & $\begin{array}{l}\text { T790M/G724S/ } \\
\text { osimertinib }\end{array}$ & - & $5.3 \% / 49.6 \%$ \\
\hline Fassunke $^{29}$ & 169 & - & IV & _/erlotinib & $\begin{array}{l}\text { T790M/G724S/ } \\
\text { osimertinib }\end{array}$ & - & _/39.3\% \\
\hline
\end{tabular}

Abbreviations: TKIs, tyrosine kinase inhibitors; F, female; M, male; MAF, mutant allele frequency; _, not mentioned.

treatment, G724S clone significantly increased after osimertinib resistance, which further implicated G724S mutation could potentially be resistant to osimertinib. ${ }^{27} \mathrm{Li}$ et al subsequently reported 5 cases of G724S mutation in 1,170 NSCLC patients. ${ }^{28}$ Surprisingly, these G724S mutations were exclusively presented in patients after resistance to gefitinib or erlotinib, ${ }^{28}$ and the G724S mutation frequencies varied drastically. The allelic frequency for tissue-based assay presents the percentage of DNA obtained from mutationcontaining tumor, which is easy to be affected by which tumor biopsy was performed. Very recently, Fassunke et al also reported four cases with G724S mutation, two of whom acquired G724S mutation after third-EGFR TKIs, including osimertinib and EGF816. Another two cases were detected with G724S in the same time with T790M after gefitinib or erlotinib resistance (Table 2). ${ }^{29}$ It can be assumed that EGFR G724S mutation may be an extremely rare mutation induced by EGFR-TKIs, including different generations of TKIs. EGFR G724S may be assumed as an oncogenic mutation as it is also within the ATP binding-loop of the kinase, ${ }^{30}$ which confers drug resistance to TKIs by either changing the protein structure, or enhancing ATP affinity or stabilizing active mutation. Fassunke et al demonstrated that EGFR G724S limited the activities of third-generation EGFR TKI inhibitors both in vitro and in vivo. Structural analyses and computational modeling indicated that EGFR G724S might induce conformation of the glycine-rich loop, which disrupted the binding with third-generation TKIs. ${ }^{29}$ More studies about structure and mechanisms should be performed to determine the precise effects conferred by this mutation.

\section{Conclusion}

In conclusion, we should make best use of the highly advanced tools for lung cancer, like ctDNA and NGS, to discover therapeutic benefits of drugs and variations of the diseases. EGFR G724S has been reported to show potential resistance to osimertinib, but more studies should be performed to explore the mechanisms conferred by this mutation in regards to osimertinib resistance.

\section{Ethics approval and consent to participate}

Research reported in the study was approved by Review Board of Xiangya Hospital, Central South University. 


\section{Consent for publication}

Documented written consent from the patient was obtained to report the details of the case.

\section{Data sharing statement}

All data generated or analyzed during this study are included in this published article.

\section{Acknowledgments}

The authors thank Abira Afzal Choudhry and Heather Chen for helping to polish the language. We greatly appreciate the patient and her family for their kind cooperation. The present study was supported by grants from the Central South University Innovation Foundation for Postgraduates (\#2017zzts209).

\section{Author contributions}

All authors contributed to data analysis, drafting or revising the article, gave final approval of the version to be published, and agree to be accountable for all aspects of the work.

\section{Disclosure}

The authors report no conflicts of interest in this work.

\section{References}

1. Rosell R, Carcereny E, Gervais R, et al. Erlotinib versus standard chemotherapy as first-line treatment for European patients with advanced EGFR mutation-positive non-small-cell lung cancer (EURTAC): a multicentre, open-label, randomised phase 3 trial. Lancet Oncol. 2012;13(3):239-246.

2. Takano T, Ohe Y, Sakamoto H, et al. Epidermal growth factor receptor gene mutations and increased copy numbers predict gefitinib sensitivity in patients with recurrent non-small-cell lung cancer. J Clin Oncol. 2005;23(28):6829-6837.

3. Kobayashi S, Boggon TJ, Dayaram T, et al. EGFR mutation and resistance of non-small-cell lung cancer to gefitinib. N Engl J Med. 2005; 352(8):786-792.

4. Kosaka T, Yatabe Y, Endoh H, et al. Analysis of epidermal growth factor receptor gene mutation in patients with non-small cell lung cancer and acquired resistance to gefitinib. Clin Cancer Res. 2006;12(19): 5764-5769.

5. Soria JC, Ohe Y, Vansteenkiste J, et al. Osimertinib in untreated $E G F R$ mutated advanced non-small-cell lung cancer. $N$ Engl J Med. 2018; 378(2):113-125.

6. Jänne PA, Yang JC, Kim DW, et al. AZD9291 in EGFR inhibitor-resistant non-small-cell lung cancer. $N$ Engl J Med. 2015;372(18):1689-1699.

7. Yu HA, Tian SK, Drilon AE, et al. Acquired resistance of EGFR-mutant lung cancer to a T790M-specific EGFR inhibitor: emergence of a third mutation (C797S) in the EGFR tyrosine kinase domain. JAMA Oncol. 2015;1(7):982-984.

8. Song HN, Jung KS, Yoo KH, et al. Acquired C797S mutation upon treatment with a T790M-specific third-generation EGFR inhibitor (HM61713) in non-small cell lung cancer. J Thorac Oncol. 2016;11(4): e45-e47.

9. Wu YL, Ahn MJ, Garassino MC, et al. CNS efficacy of osimertinib in patients with T790M-positive advanced non-small-cell lung cancer: Data from a randomized phase III trial (AURA3). J Clin Oncol. 2018; 36(26):2702-2709.
10. Bersanelli M, Minari R, Bordi P, et al. L718Q mutation as new mechanism of acquired resistance to AZD9291 in EGFR-mutated NSCLC. J Thorac Oncol. 2016;11(10):e121-e123.

11. Sharma SV, Bell DW, Settleman J, Haber DA. Epidermal growth factor receptor mutations in lung cancer. Nat Rev Cancer. 2007;7(3): 169-181.

12. Costa DB, Kobayashi SS. Whacking a mole-cule: clinical activity and mechanisms of resistance to third generation EGFR inhibitors in EGFR mutated lung cancers with EGFR-T790M. Transl Lung Cancer Res. 2015;4(6):809-815.

13. Thress KS, Paweletz CP, Felip E, et al. Acquired EGFR C797S mutation mediates resistance to AZD9291 in non-small cell lung cancer harboring EGFR T790M. Nat Med. 2015;21(6):560-562.

14. Niederst MJ, Hu H, Mulvey HE, et al. The allelic context of the C797S mutation acquired upon treatment with third-generation EGFR inhibitors impacts sensitivity to subsequent treatment strategies. Clin Cancer Res. 2015;21(17):3924-3933.

15. Chabon JJ, Simmons AD, Lovejoy AF, et al. Circulating tumour DNA profiling reveals heterogeneity of EGFR inhibitor resistance mechanisms in lung cancer patients. Nat Commun. 2016;7(1):11815.

16. Tan DSW, Kim DW, Leighl NB, et al. Genomic profiling of resistant tumor samples following progression on EGF816, a third generation, mutant-selective EGFR tyrosine kinase inhibitor, in advanced non-small cell lung cancer. 2017 ASCO Annual Meeting. J Clin Oncol. 2017; 35(15_suppl):11506-11506.

17. Menon R, Müller J, Schneider P, et al. A novel EGFR (C797) variant detected in a pleural biopsy specimen from an osimertinib-treated patient using a comprehensive hybrid capture-based next-generation sequencing assay. J Thorac Oncol. 2016;11(9):e105-e107.

18. Chen K, Zhou F, Shen W, et al. Novel mutations on EGFR Leu792 potentially correlate to acquired resistance to osimertinib in advanced NSCLC. J Thorac Oncol. 2017;12(6):e65-e68.

19. Yang Z, Yang N, Ou Q, et al. Investigating novel resistance mechanisms to third-generation EGFR tyrosine kinase inhibitor osimertinib in non-small cell lung cancer patients. Clin Cancer Res. 2018;24(13): 3097-3107.

20. Ou SI, Cui J, Schrock AB, et al. Emergence of novel and dominant acquired EGFR solvent-front mutations at Gly796 (G796S/R) together with C797S/R and L792F/H mutations in one EGFR (L858R/T790M) NSCLC patient who progressed on osimertinib. Lung Cancer. 2017;108: 228-231.

21. Oxnard GR, Hu Y, Mileham KF, et al. Assessment of resistance mechanisms and clinical implications in patients with EGFR T790Mpositive lung cancer and acquired resistance to osimertinib. JAMA Oncol. 2018;4(11):1527-1534.

22. Planchard D, Loriot $Y$, André F, et al. EGFR-independent mechanisms of acquired resistance to AZD9291 in EGFR T790M-positive NSCLC patients. Ann Oncol. 2015;26(10):2073-2078.

23. Kim TM, Song A, Kim DW, et al. Mechanisms of acquired resistance to AZD9291: a mutation-selective, irreversible EGFR inhibitor. J Thorac Oncol. 2015;10(12):1736-1744.

24. Ho CC, Liao WY, Lin CA, Shih JY, Yu CJ, Chih-Hsin Yang J. Acquired BRAF V600E mutation as resistant mechanism after treatment with osimertinib. J Thorac Oncol. 2017;12(3):567-572.

25. Ham JS, Kim S, Kim HK, et al. Two cases of small cell lung cancer transformation from EGFR mutant adenocarcinoma during AZD9291 treatment. J Thorac Oncol. 2016;11(1):e1-e4.

26. Oztan A, Fischer S, Schrock AB, et al. Emergence of EGFR G724S mutation in EGFR-mutant lung adenocarcinoma post progression on osimertinib. Lung Cancer. 2017;111:84-87.

27. Peled N, Roisman LC, Miron B, et al. Subclonal therapy by two EGFR TKIs guided by sequential plasma cell-free DNA in EGFR-mutated lung cancer. $J$ Thorac Oncol. 2017;12(7):e81-e84.

28. Li J, Wang Z, Groen HJM, et al. Uncommon EGFR G724S mutations arise in non-small-cell lung cancer patients with acquired resistance to first-generation EGFR-TKIs. Lung Cancer. 2018;118: $173-175$. 
29. Fassunke J, Müller F, Keul M, et al. Overcoming EGFR ${ }^{\mathrm{G} 724 \mathrm{~s}}$-mediated osimertinib resistance through unique binding characteristics of secondgeneration EGFR inhibitors. Nat Commun. 2018;9(1):4655.
30. ManChon U, Talevich E, Katiyar S, Rasheed K, Kannan N. Prediction and prioritization of rare oncogenic mutations in the cancer Kinome using novel features and multiple classifiers. PLoS Comput Biol. 2014;10(4):e1003545.

\section{Publish your work in this journal}

OncoTargets and Therapy is an international, peer-reviewed, open access journal focusing on the pathological basis of all cancers, potential targets for therapy and treatment protocols employed to improve the management of cancer patients. The journal also focuses on the impact of management programs and new therapeutic agents and protocols on

\section{Dovepress}

patient perspectives such as quality of life, adherence and satisfaction. The manuscript management system is completely online and includes a very quick and fair peer-review system, which is all easy to use. Visit http://www.dovepress.com/testimonials.php to read real quotes from published authors. 